\title{
Determination of the effects of cinnamon bark fractions on Candida albicans and oral epithelial cells
}

\author{
Marie-Pier Veilleux and Daniel Grenier ${ }^{*}$ (D)
}

\begin{abstract}
Background: Candida albicans is an opportunistic pathogen that causes oral candidiasis and denture stomatitis. It has also been reported to infect oral mucositis lesions in patients who suffer from cancer affecting the head and neck and who receive chemotherapy and radiotherapy treatments. This study aimed to investigate the effects of two cinnamon bark fractions, i.e., an essential oil and an aqueous extract enriched in proanthocyanidins (Cinnulin $\mathrm{PF}^{\oplus}$ ) on growth, biofilm formation, and adherence properties of $C$. albicans as well as on oral epithelial cells (barrier integrity, inflammatory response).

Methods: A microplate dilution assay was used to determine antifungal and anti-biofilm properties. A fluorescent assay was used to determine C. albicans adherence to oral epithelial cells. Cytotoxicity toward oral epithelial cells was assessed by determination of cell metabolic activity. Tight junction integrity of gingival keratinocytes was assessed by determination of transepithelial electrical resistance. IL-6 and IL-8 secretion by TNFa-stimulated oral epithelial cells was quantified by ELISA.
\end{abstract}

Results: While Cinnulin $\mathrm{PF}^{\circledR}$ did not reduce C. albicans growth, the cinnamon bark oil exhibited high antifungal activity with minimum inhibitory concentrations and minimum fungicidal concentrations in the range of 0.039 to $0.078 \%$. The cinnamon oil was also active against a pre-formed C. albicans biofilm. Interestingly, Cinnulin PF ${ }^{\circledR}$ prevented biofilm formation by C. albicans and attenuated its adherence to oral epithelial cells. At their effective concentrations, the cinnamon oil and the Cinnulin $\mathrm{PF}^{\oplus}$ displayed no significant cytotoxicity against oral epithelial cells. In an in vitro model, both cinnamon fractions reinforced the integrity of the oral epithelial barrier. Lastly, Cinnulin PF ${ }^{\circledast}$ inhibited the secretion of interleukin- 6 and interleukin-8 by oral epithelial cells stimulated with TNF-a.

Conclusion: By their ability to attenuate growth, biofilm formation and adherence property of C. albicans, to reinforce the epithelial barrier function, and to exert anti-inflammatory properties the two cinnamon fractions (essential oil, Cinnulin $\mathrm{PF}^{\circledast}$ ) investigated in the present study may be promising agents for treating oral infections involving C. albicans.

Keywords: Biofilm, Candida albicans, Cinnamon, Essential oil, Epithelial cells, Polyphenols

\section{Background}

Candida albicans is a commensal fungus that colonizes oral mucosal surfaces and that is normally harmless in healthy individuals as it is maintained at low levels by specific and non-specific salivary and mucosal defense mechanisms as well as by competitive inhibition by oral bacteria [1]. However, under certain circumstances, this opportunistic microorganism can cause a superficial

\footnotetext{
* Correspondence: daniel.grenier@greb.ulaval.ca

Oral Ecology Research Group, Faculty of Dentistry, Université Laval, 2420 Rue de la Terrasse, Quebec City, QC G1V 0A6, Canada
}

infection called candidiasis. Oral candidiasis is characterized by the appearance of white plaques on inflamed and red mucosa (inner cheeks, tongue, throat) and by pain when eating or swallowing $[1,2]$. If the infection becomes invasive, which can occur in immunologically and medically compromised individuals, it can cause septicemia leading to organ failure and eventually death [3]. C. albicans has also been reported to infect oral mucositis lesions $[4,5]$, causing inflammation of the oropharyngeal mucosa $[6,7]$. Patients who suffer from cancer affecting the head

(c) The Author(s). 2019 Open Access This article is distributed under the terms of the Creative Commons Attribution 4.0 International License (http://creativecommons.org/licenses/by/4.0/), which permits unrestricted use, distribution, and reproduction in any medium, provided you give appropriate credit to the original author(s) and the source, provide a link to the Creative Commons license, and indicate if changes were made. The Creative Commons Public Domain Dedication waiver (http://creativecommons.org/publicdomain/zero/1.0/) applies to the data made available in this article, unless otherwise stated. 
and neck and who receive chemotherapy and radiotherapy treatments are almost all affected by oral mucositis $[6,7]$.

C. albicans produces several virulence factors that play critical roles in the pathogenic process leading to superficial or systemic infections [8]. The cell surface adhesins of C. albicans allow initial adhesion to oral epithelial cells, a key step prior to subsequent tissue invasion and damage [8-10]. C. albicans can form biofilms on biotic and abiotic oral surfaces; this increases the resistance of the fungus to antimicrobial agents and the host immune system $[2,11,12]$. Additional virulence factors produced by $C$. albicans include its ability to switch from the yeast form to an invasive hyphae morphotype and to secrete proteolytic and lipolytic enzymes [8]. These pathogenic determinants may be potential targets for new antifungal agents that may limit the appearance of strains resistant to conventional antifungals.

Despite the availability of antifungal agents to treat $C$. albicans-associated oral infections, treatment failures are increasingly common due to the emergence of resistant strains [13-15]. Given this, investigations of the antifungal potential of new molecules are highly relevant. In recent years, plant-derived compounds with antifungal potential have attracted the interest of researchers [16]. Cinnamon, a spice derived from the inner bark of the cinnamon tree, has been reported to possess a number of therapeutic properties, including antimicrobial activity $[17,18]$. In the present study, we investigated the effects of two cinnamon bark fractions, an essential oil and an aqueous extract enriched in proanthocyanidins, on the growth, biofilm formation, and adherence properties of C. albicans. In addition, an oral epithelial cell model was used to study the effects of the two fractions on the integrity of the epithelial barrier and the host inflammatory response.

\section{Methods}

\section{Source of cinnamon fractions}

A cinnamon extract commercialized as Cinnulin $\mathrm{PF}^{\circ}$ (Lot \#: CNCP 1604003) was kindly provided by IN Ingredients Inc. (Spring Hill, TN, USA). The aqueous extract, which was prepared from the bark of Cinnamomum burmannii, contains $531.9 \mathrm{mg} / \mathrm{g}$ of proanthocyanidins according to the datasheet provided by the company. Cinnamon bark is relatively unusual as it contains proanthocyanidins with a high number of A-type bonds [19]. A $20 \mathrm{mg} / \mathrm{mL}$ stock solution of the extract was prepared in $50 \%(\mathrm{v} / \mathrm{v})$ dimethylsulfoxide and was sterilized by filtration $(0.22-\mu \mathrm{m}$ pore size). Carrier solvent was used as a control in all assays. A cinnamon bark essential oil (Lot \#: BHC09A4) extracted from Cinnamomum verum, was purchased from Hunzaroma (Longueuil, QC, Canada). The chromatographic analysis performed by the company showed that the cinnamon oil contained cinnamaldehyde $(71.35 \%[\mathrm{v} / \mathrm{v}])$, eugenol (6.18\%), linolol (6.02), $\beta$-caryophyllene (6.02\%), cinnamyle acetate $(4.04 \%)$, benzyle benzoate $(0.96 \%)$, pcymene $(0.56 \%)$, and 1,8 -cineol $(0.55 \%)$.

\section{C. albicans and culture conditions}

C. albicans ATCC 28366 (reference strain) and LAM-1 (clinical strain from a case of systemic candidiasis) were cultivated in Sabouraud dextrose medium (BBL Microbiology Systems, Cockeysville, MD, USA) at $\mathrm{pH} 7$ and $37^{\circ} \mathrm{C}$.

\section{Determination of the minimum inhibitory and minimum fungicidal concentrations}

The minimum inhibitory concentration (MIC) and minimum fungicidal concentration (MFC) were determined using a microplate dilution assay. To determine the MIC value, a 24-h culture of $C$. albicans was diluted in fresh culture medium (Sabouraud dextrose medium) to an optical density at $660 \mathrm{~nm}\left(\mathrm{OD}_{660}\right)$ of 0.2 corresponding to a 1 McFarland standard. Aliquots $(100 \mu \mathrm{L})$ of C. albicans were added to an equal volume of serial dilutions in culture medium of cinnamon oil (1.25 to $0.0195 \%)$ or Cinnulin $\mathrm{PF}^{\circ}(1000$ to $62.5 \mu \mathrm{g} / \mathrm{mL})$ in 96 -well microplates. Wells without $C$. albicans or without the cinnamon fractions were used as controls. When testing the cinnamon oil, the microplate was covered with an adhesive film to avoid evaporation of the volatile compounds. After an incubation at $37^{\circ} \mathrm{C}$ for $24 \mathrm{~h}$ (stationary growth phase), growth was monitored by recording the $\mathrm{OD}_{660}$ using a microplate reader (Bio-Rad Laboratories, Mississauga, ON, Canada). The MIC value corresponded to the lowest concentration of the cinnamon fractions that completely inhibited growth. To determine the MFC, $5 \mu \mathrm{L}$ from wells showing no visible growth was spotted on Sabouraud dextrose agar plates, which were incubated at $37^{\circ} \mathrm{C}$ for 3 days. The MFC value corresponded to the lowest concentration of the cinnamon fractions where no colony formation was observed. The antifungal agent nystatin was used as a reference antifungal. The MFC/ MIC ratio was calculated, and a compound or fraction was considered fungicidal when the ratio was $\leq 4$ and fungistatic when the ratio was $>4$ [20]. All assays were performed in triplicate to ensure reproducibility.

\section{Membrane permeability}

The ability of the cinnamon oil at MFC to permeabilize the membrane of C. albicans ATCC 28366 was evaluated using SYTOX Green dye (Life Technologies Inc., Burlington, ON, Canada), which binds to DNA once the membrane has been compromised. The assay was performed as previously described [21]. The fluorescence resulting from the binding of the dye to DNA was recorded using a Synergy 2 microplate reader (BioTek Instruments, Winooski, VT, USA) every $15 \mathrm{~min}$ for $2 \mathrm{~h}$ with the excitation wavelength set at $485 \mathrm{~nm}$ and the 
emission wavelength set at $528 \mathrm{~nm}$. A reaction mixture without essential oil was used as a negative control.

\section{Biofilm formation and killing}

The effect of the cinnamon fractions on biofilm formation by C. albicans ATCC 28366 was determined by growing microorganisms in Sabouraud dextrose medium in a 96-well plate in the presence of two-fold serial dilutions of the compounds. Following a 24-h incubation at $37^{\circ} \mathrm{C}$, the medium and free-floating microorganisms were removed by aspiration using a $26 \mathrm{~g}$ needle, and the wells were washed three times with distilled water. Biofilms were stained with $100 \mu \mathrm{L}$ of $0.01 \%$ crystal violet for $15 \mathrm{~min}$. The wells were then washed three times with distilled water and were dried at $37^{\circ} \mathrm{C}$ overnight, after which $100 \mu \mathrm{L}$ of $75 \%$ ethanol $(\mathrm{v} / \mathrm{v})$ was added to each well to release the dye from the biofilm. Absorbance at $550 \mathrm{~nm}\left(\mathrm{~A}_{550}\right)$ was then measured using a microplate reader. The effect of the cinnamon fractions on biofilm formation was also examined by scanning electron microscopy using the protocol previously described by Lagha et al. [22]. Samples were examined using a JEOL JSM6360LV scanning electron microscope operating at $30 \mathrm{kV}$. The ability of the cinnamon oil to kill a pre-formed $C$. albicans biofilm was also investigated. Biofilms were prepared in a 96-well plate by cultivating C. albicans in Sabouraud dextrose medium for $24 \mathrm{~h}$ prior to treatment $(1 \mathrm{~h})$ with the cinnamon oil at the MFC value. Biofilm viability was then measured with an XTT [2,3-bis(2-methoxy-4nitro-sulfophenyl)-2H-tetrazolium-5-carboxanilide sodium salt] assay, as described previously [23].

\section{Epithelial cell culture conditions and viability assays}

The human oral epithelial cell line B11, which was kindly provided by S. Groeger (Justus Liebig University Giessen, Germany) and has already been characterized [24], was cultured in keratinocyte serum-free medium (K-SFM; Life Technologies Inc.) supplemented with growth factors $(50 \mu \mathrm{g} / \mathrm{mL}$ of bovine pituitary extract and $5 \mathrm{ng} / \mathrm{mL}$ of human epidermal growth factor) and $100 \mu \mathrm{g} /$ $\mathrm{mL}$ of penicillin G-streptomycin. The human oral epithelial cell line GMSM-K [25] was kindly provided by V. Murrah (University of North Carolina, Chapel Hill, NC, USA) and was cultivated in Dulbecco's Modified Eagle's Medium (DMEM) supplemented with 10\% heatinactivated inactivated fetal bovine serum (FBS) and $100 \mu \mathrm{g} / \mathrm{mL}$ of penicillin G-streptomycin. The cell cultures were incubated at $37^{\circ} \mathrm{C}$ in a $5 \% \mathrm{CO}_{2}$ atmosphere. Epithelial cells $\left(1 \times 10^{5}\right.$ cells in $\left.200 \mu \mathrm{L}\right)$ were seeded into the wells of a 96-well tissue culture plate and were cultivated until they reached confluence. The cells were then treated with either Cinnulin $\mathrm{PF}^{\oplus}(0,125,250,500$, $1000 \mu \mathrm{g} / \mathrm{mL})$ or cinnamon oil $(0,0.0078,0.0156,0.0313$,
$0.0625,0.125 \%)$ in the appropriate culture medium for $24 \mathrm{~h}$. Their viability was then determined using an MTT (3-[4,5-diethylthiazol-2-yl]-2,5diphenyltetrazolium bromide) colorimetric assay according to the manufacturer's protocol (Roche Diagnostics, Laval, QC, Canada).

\section{Adherence to epithelial cells}

The effect of the cinnamon fractions on the adherence of C. albicans ATCC 28366 to oral epithelial cells was assessed using the human GMSM-K cell line. Epithelial cells were seeded $\left(5 \times 10^{4}\right.$ cells/well $)$ in a 96-well clear bottom black microplate (Greiner Bio One, Frickenhausen, Germany) and were incubated at $37^{\circ} \mathrm{C}$ in a $5 \% \mathrm{CO}_{2}$ atmosphere until they reached confluence. The wells were then washed with DMEM-1\% heat-inactivated FBS and were blocked with $1 \%$ bovine serum albumin (BSA) to prevent non-specific fungal adherence, and the cinnamon fractions diluted in DMEM-1\% heat-inactivated FBS medium were added. Wells without the cinnamon fractions were used as controls. In parallel, cells from an overnight culture of C. albicans were labeled with fluorescein isothiocyanate (FITC; Sigma-Aldrich Canada Co.) according to a protocol routinely used in our laboratory [26]. FITC-labeled C. albicans was added at a multiplicity of infection (MOI) of 100 to wells containing an epithelial cell monolayer (in the absence or presence of the cinnamon fractions). Following an incubation for $4 \mathrm{~h}$ at $37^{\circ} \mathrm{C}$, unbound C. albicans were aspirated, and the wells were washed three times with $50 \mathrm{mM}$ phosphatebuffered saline ( $\mathrm{pH} 7$; PBS). Adhered C. albicans were determined by monitoring fluorescence using a Synergy 2 microplate reader with the excitation and emission wavelengths set at 488 and $522 \mathrm{~nm}$, respectively. Adhered FITC-labeled C. albicans were also observed using an Olympus FSX100 fluorescence microscope (Olympus Canada Inc., Richmond Hill, ON, Canada).

\section{Oral epithelial barrier integrity}

The effect of the cinnamon fractions on the integrity of the epithelial barrier was assessed using the human B11 cell line described above and the protocol previously described by Ben Lagha and Grenier [27]. Briefly, epithelial cells $\left(3.5 \times 10^{5}\right.$ cells/insert $)$ were seeded in Costar Transwell ${ }^{\text {TM }}$ plates with clear polyester membrane inserts $(6.5-\mathrm{mm}$ diameter, $0.4-\mu \mathrm{m}$ pore size; Corning Co., Cambridge, MA, USA). The basolateral and apical compartments were filled with $0.6 \mathrm{~mL}$ and $0.1 \mathrm{~mL}$ of culture medium, respectively. Following a 3-day incubation to allow the cells to form tight junctions, the conditioned medium was replaced with antibiotic-free $\mathrm{K}-\mathrm{SFM}$, and the cells were incubated for a further $16 \mathrm{~h}$. The cinnamon fractions were then added, and the integrity of the epithelial tight junctions was determined by monitoring the transepithelial electrical resistance 
(TER) using an ohmmeter (EVOM2, World Precision Instruments, Sarasota, FL, USA) after 2 and $4 \mathrm{~h}$ of incubation at $37^{\circ} \mathrm{C}$ in a $5 \% \mathrm{CO}_{2}$ atmosphere. Resistance values were calculated in Ohms $(\Omega) / \mathrm{cm}^{2}$ by multiplying the resistance values by the surface area of the membrane filter. Results are expressed as a percentage of the basal control value measured at time $0 \quad(100 \%$ value).

\section{Secretion of cytokines by oral epithelial cells}

The effect of the cinnamon fractions on the secretion of the pro-inflammatory cytokines interleukin 6 (IL-6) and interleukin 8 (IL-8) was investigated using the GMSM-K epithelial cell line. Cells were seeded in a 6-well plate $\left(10^{6}\right.$ cells/well in $\left.2 \mathrm{~mL}\right)$ and were cultured overnight at $37^{\circ} \mathrm{C}$ in a $5 \% \mathrm{CO}_{2}$ atmosphere to allow cell adhesion. The epithelial cells were pre-treated with the cinnamon fractions for $30 \mathrm{~min}$ prior to stimulating them with $1 \mathrm{ng} /$ $\mathrm{mL}$ of recombinant human TNF- $\alpha$ (AnaSpec, Fremont, CA, USA). After a 24-h incubation, cell-free supernatants were collected and were stored at $-20^{\circ} \mathrm{C}$ until used. Commercial enzyme-linked immunosorbent assay (ELISA) kits (R\&D Systems, Minneapolis, MN, USA) were used to quantify IL- 6 and IL- 8 concentrations according to the manufacturer's protocols.

\section{Statistical analysis}

Unless indicated otherwise, all assays were performed in triplicate in two independent experiments, and the means \pm standard deviations were calculated. Statistical analyses were performed using a one-way analysis of variance with a post hoc Bonferroni multiple comparison (GraphPad Software Inc.; La Jolla, CA, USA). All results were considered statistically significant at $p<0.01$.

\section{Results}

The antifungal activity of the cinnamon fractions is reported in Table 1 . While Cinnulin $\mathrm{PF}^{\circ}$ at concentrations up to $1000 \mu \mathrm{g} / \mathrm{mL}$ did not reduce the growth of either strain of C. albicans, the cinnamon bark oil displayed high antifungal activity, with MIC and MFC values in the range of 0.039 to $0.078 \%(\mathrm{v} / \mathrm{v})$. Nystatin, which was used as a reference antifungal agent, had a MIC of $50 \mu \mathrm{g} / \mathrm{mL}$ and an MFC of $200 \mu \mathrm{g} / \mathrm{mL}$. Cinnamon oil is fungicidal rather than fungistatic, with an MFC/MIC ratio in the range of 1 to 2 .

SYTOX $^{\circ}$ Green dye is a fluorescent molecule that penetrates impaired cytoplasmic membranes, binds to DNA, and emits fluorescence. When the $C$. albicans cells were treated with cinnamon oil, a time-dependent increase in fluorescence occurred, suggesting that their membranes had been permeabilized due to the fungicidal activity of the cinnamon oil (Fig. 1). No significant increase in fluorescence occurred in the negative control over the 2$\mathrm{h}$ incubation period. Cinnulin $\mathrm{PF}^{\circ}$, which had no antimicrobial effect on C. albicans, also did not cause an increase in fluorescence (data not shown).

The effect of Cinnulin $\mathrm{PF}^{\circ}$ and cinnamon bark oil on biofilm formation by $C$. albicans was then investigated. Although Cinnulin $\mathrm{PF}^{\circ}$ did not reduce the growth of $C$. albicans, it significantly attenuated biofilm formation as determined by crystal violet staining (Fig. 2a). More specifically, at a Cinnulin $\mathrm{PF}^{\odot}$ concentration of $62.5 \mu \mathrm{g} / \mathrm{mL}$, biofilm formation was reduced by $91 \%$. The effect of Cinnulin $\mathrm{PF}^{\bullet}$ on biofilm formation by $C$. albicans was also visualized by scanning electron microscopy. The control biofilm of C. albicans appeared dense, and hyphae were an important structural component (Fig. 3a and $b)$. Electron micrographs clearly showed the marked reduction in mature biofilm when $C$. albicans was grown in the presence of $62.5 \mu \mathrm{g} / \mathrm{mL}$ of Cinnulin $\mathrm{PF}^{\oplus}$ (Fig. 3c and $\mathrm{d})$. In addition, no hyphae were observed. The cinnamon bark oil also attenuated biofilm formation by $C$. albicans at concentrations that did not inhibit growth. The formation of biofilm was reduced by $86 \%$ when $C$. albicans was grown in the presence of $0.0049 \%$ cinnamon oil (Fig. 2b).

Given the fungicidal activity of the cinnamon bark oil, we determined whether it could kill C. albicans biofilms. Since Cinnulin $\mathrm{PF}^{\circ}$ did not show any antimicrobial effect against C. albicans, it was not tested in this analysis. A 24-h pre-formed C. albicans biofilm was treated for 60 min with cinnamon oil at its MFC. Residual viability was determined using an XTT assay that measures metabolic

Table 1 Minimum inhibitory concentrations (MIC) and minimum fungicidal concentrations (MFC) of cinnamon fractions against C. albicans

\begin{tabular}{lllllll}
\hline & \multicolumn{3}{l}{ Candida albicans } & & \\
\cline { 2 - 6 } & ATCC 28366 & & LAM-1 & \\
\hline Compounds & MIC & MFC & MFC/MIC* Ratio & MIC & MFC & MFC/MIC Ratio \\
Cinnulin PF® $(\mu \mathrm{g} / \mathrm{mL})$ & $>1000$ & $>1000$ & - & $>1000$ & $>1000$ & - \\
Cinnamon bark oil $(\%[\mathrm{v} / \mathrm{v}])$ & 0.039 & 0.078 & 2 & 0.078 & 0.078 & 1 \\
Nystatin $(\mu \mathrm{g} / \mathrm{mL})$ & 50 & 200 & 4 & 50 & 200 & 4 \\
\hline
\end{tabular}

* MFC/MIC Ratio: > 4 means fungistatic activity; $\leq 4$ means fungicidal activity 


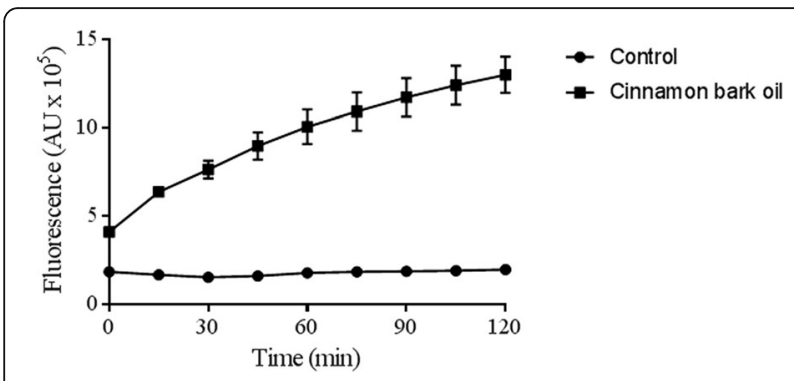

Fig. 1 Effect of cinnamon bark oil on the membrane integrity of $C$. albicans ATCC 28266 as determined using SYTOX ${ }^{\circledR}$ Green dye, which penetrates damaged cytoplasmic membranes. C. albicans cells were incubated with cinnamon oil at its MFC and fluorescence was recorded for $2 \mathrm{~h}$ activity. This treatment reduced biofilm viability by $48 \%$, but did not cause any desorption of the biofilm biomass (Fig. 4).

The effect of the cinnamon fractions on the adherence of C. albicans to oral epithelial cells (GMSM-K cell line) was then tested. Cinnulin $\mathrm{PF}^{\circ}$ dose-dependently reduced the adherence of FITC-labeled C. albicans to epithelial cells (Fig. 5a). More specifically, in the presence of $1000 \mu \mathrm{g} / \mathrm{mL}$ of Cinnulin $\mathrm{PF}^{\circ}$, adherence was inhibited by $59 \%$. The ability of Cinnulin $\mathrm{PF}^{\circ}$ to reduce the adherence of $C$. albicans to oral epithelial cells was confirmed by fluorescence microscopy (Fig. 5b). Cinnamon bark oil had no inhibitory effect on the adherence of $C$. albicans to oral epithelial cells (data not shown).

In order to investigate the biocompatibility of the cinnamon fractions, we tested their effects on the viability of two oral epithelial cell lines. Up to $1000 \mu \mathrm{g} / \mathrm{mL}$ of Cinnulin $\mathrm{PF}^{\circ}$ had no cytotoxic effect on B11 epithelial cells (Fig. 6a). However, $500 \mu \mathrm{g} / \mathrm{mL}$ of Cinnulin $\mathrm{PF}^{\circ}$
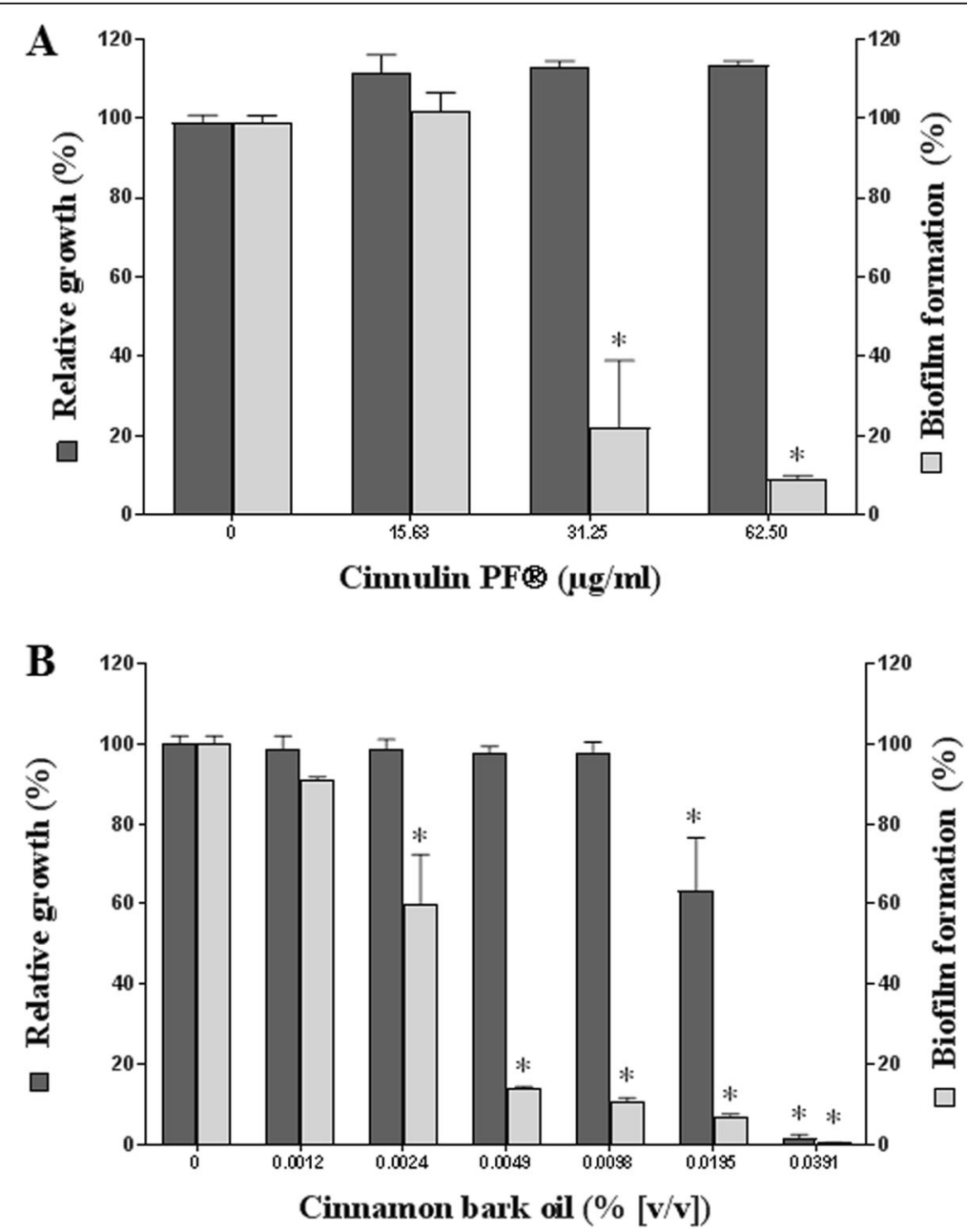

Fig. 2 Effect of Cinnulin PF ${ }^{\oplus}$ (panel a) and cinnamon bark oil (panel b) on the growth and biofilm formation of C. albicans ATCC 28266. A value of $100 \%$ was assigned to the growth and biofilm obtained in the absence of the cinnamon fractions. Results are expressed as the means \pm SD of triplicate assays from two independent experiments. *: significantly different from the control $(p<0.01)$ 

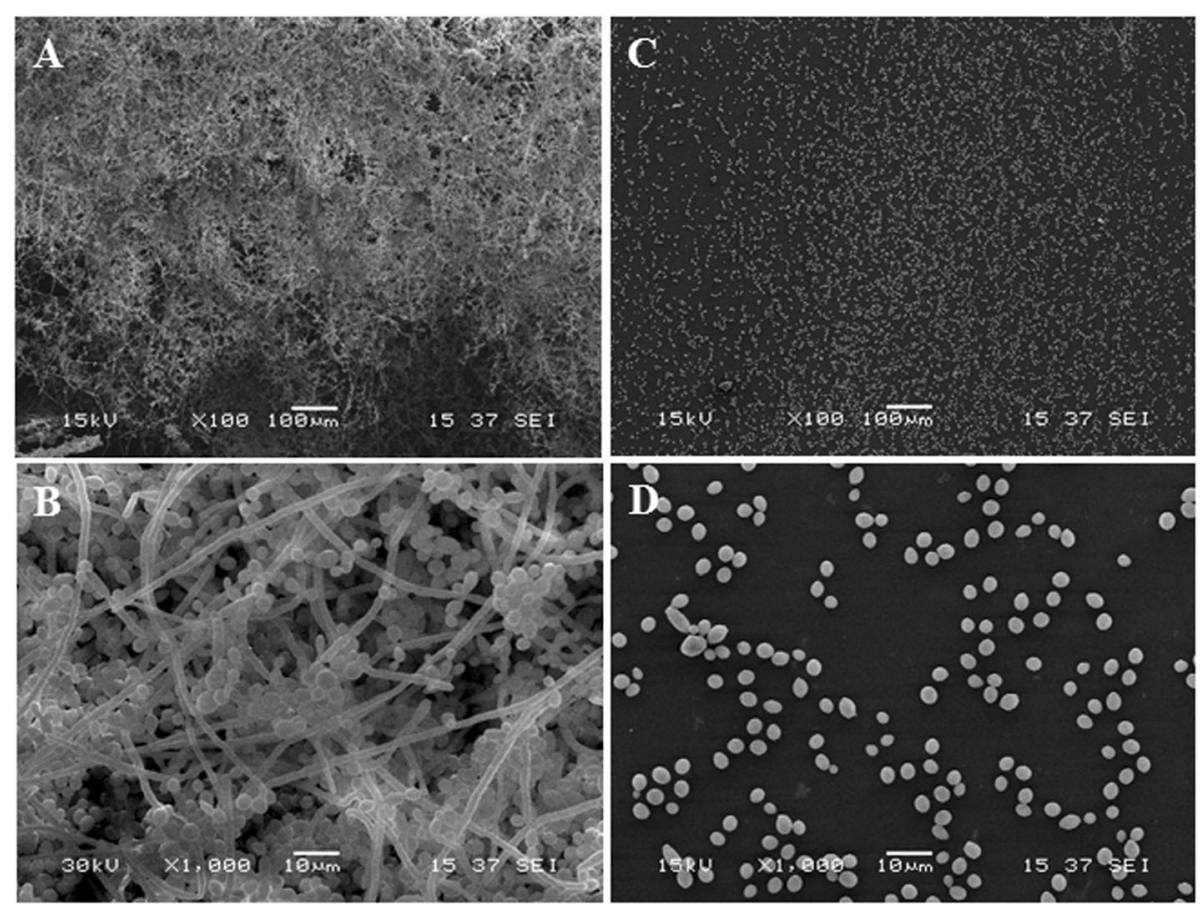

Fig. 3 Scanning electron micrographs of biofilms formed by C. albicans ATCC 28366 grown in the absence (panels $\mathbf{a}$ and $\mathbf{b}$ ) or presence of $62.5 \mathrm{\mu g} / \mathrm{mL}$ of Cinnulin PF (panels C and D). Magnification: $100 \mathrm{X}$ (panels $\mathbf{a}$ and $\mathbf{c}$ ) and $1000 \mathrm{X}$ (panels $\mathbf{b}$ and $\mathbf{d}$ )

reduced the viability of GMSM-K epithelial cells by 42.8\%. Treating the B11 and GMSM-K epithelial cell lines with $0.0625 \%$ cinnamon bark oil reduced cell viability by $14 \%$ (not significant at $p<0.01$ ) and $73.8 \%$, respectively (Fig. 6b).

We then investigated the effect of Cinnulin $\mathrm{PF}^{\bullet}$ and cinnamon bark oil on the integrity of the epithelial barrier by monitoring the TER values of the B11 cell line. After a 4-h incubation, $62.5 \mu \mathrm{g} / \mathrm{mL}$ and $125 \mu \mathrm{g} /$ $\mathrm{mL}$ of Cinnulin $\mathrm{PF}^{\bullet}$ time-dependently increased the TER values of the B11 cell line by 42.9 and 39.5\%, respectively (Fig. 7), while $0.0156 \%$ cinnamon oil increased the TER value by $43.9 \%$.

We assessed the anti-inflammatory properties of Cinnulin $\mathrm{PF}^{\circ}$ using an oral epithelial cell model (GMSM-K cell line) stimulated with TNF- $\alpha$. Stimulating the epithelial cells with $1 \mathrm{ng} / \mathrm{mL}$ of TNF- $\alpha$ induced the secretion of IL-6 $(670 \mathrm{pg} / \mathrm{mL})$ and IL-8 $(15,008 \mathrm{pg} / \mathrm{mL})$. A 30 -min pre-treatment with $62.5 \mu \mathrm{g} / \mathrm{mL}$ of Cinnulin $\mathrm{PF}^{\circ}$ prior to stimulating the epithelial cells with TNF- $\alpha$ reduced the secretion of IL- 6 and IL- 8 by 29 and $57 \%$, respectively (Fig. 8) while $250 \mu \mathrm{g} / \mathrm{mL}$ of Cinnulin $\mathrm{PF}^{\bullet}$

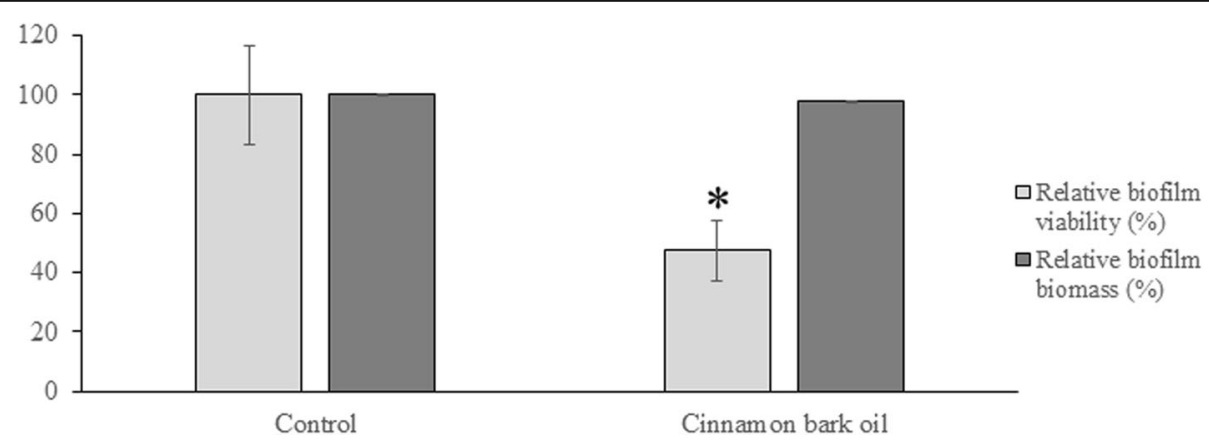

Fig. 4 Effect of cinnamon bark oil on the viability and desorption of a C. albicans ATCC 28366 biofilm. A pre-formed (24 h) C. albicans biofilm was treated for 60 min with cinnamon oil at its MFC, and the residual biomass and viability were measured by crystal violet staining and an XTT assay, respectively. A value of $100 \%$ was assigned to the pre-formed biofilm exposed to the cinnamon oil carrier solvent. The assays were performed in triplicate, and the mean \pm SD of two independent experiments was calculated. *: significantly different from the control $(p<0.01)$ 


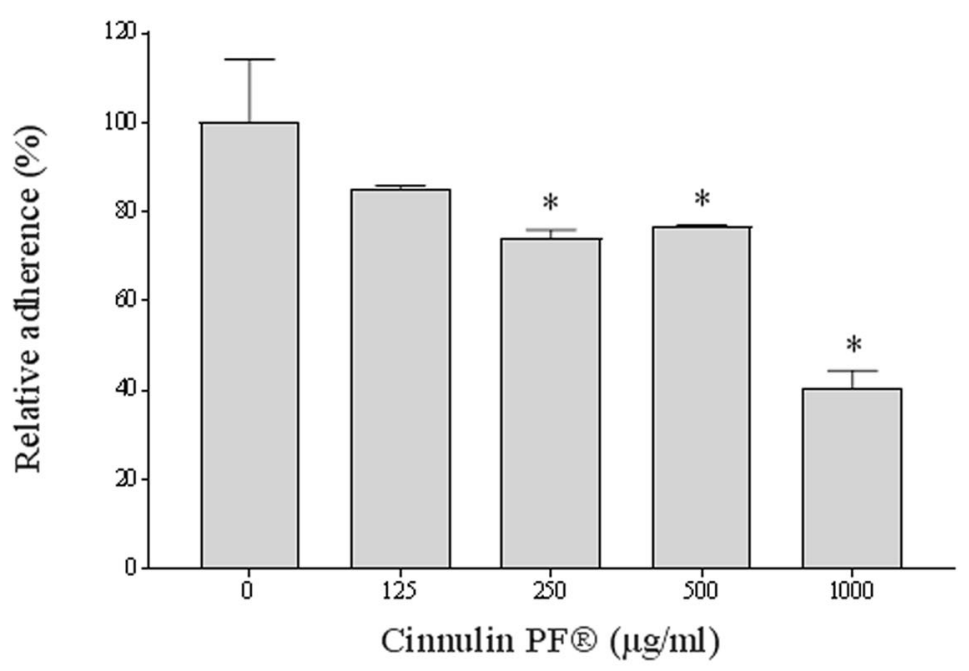

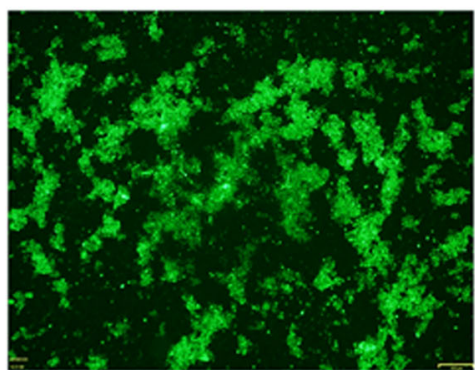

Control

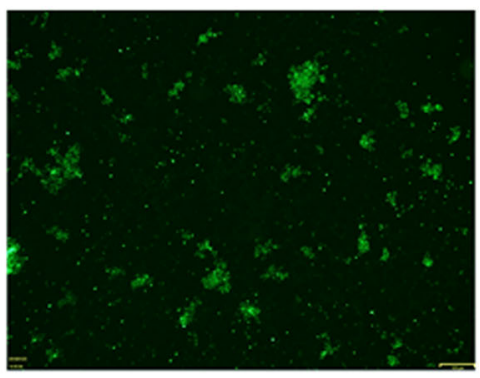

+ Cinnulin PF@ $(125 \mu \mathrm{g} / \mathrm{ml})$

Fig. 5 Effect of Cinnulin PF ${ }^{\circledR}$ on the adherence of C. albicans ATCC 28366 to GMSM-K oral epithelial cells. Panel A: FITC-labeled C. albicans cells adhered to epithelial cells were quantified by measuring fluorescence using a microplate reader. A value of 100\% was assigned to C. albicans adhered to epithelial cells in the absence of Cinnulin PF ${ }^{\circledR}$. Results are expressed as the means \pm SD of triplicate assays from two independent experiments. *: significantly different from the control $(p<0.01)$. Panel B: Fluorescence micrograph of FITC-labeled C. albicans cells adhered to epithelial cells

almost totally inhibited the secretion of the two cytokines. The cinnamon bark oil did not reduce the secretion of IL- 6 or IL-8 at non-cytotoxic concentrations $(\leq 0.0078 \%$; data not shown).

\section{Discussion}

C. albicans can be isolated from various sites in humans. It is an opportunistic pathogen and has been associated with superficial and systemic infections, especially in immunologically or medically compromised individuals $[3,11]$. C. albicans causes oral candidiasis and denture stomatitis, and may also be involved in dental caries, periodontal diseases, and refractory endodontic infections [2]. Ulcerative oral lesions (oral mucositis) resulting from chemotherapy and radiotherapy treatments are susceptible to secondary infections by oral microorganisms, including C. albicans $[4,5]$. For instance, Belazi et al. [28] isolated Candida spp. from oral mucositis lesions in $77 \%$ of patients undergoing radiotherapy for head and neck cancer.
C. albicans infections can generally be successfully treated with conventional antifungal agents. However, the emergence of resistance to these therapeutic agents is of increasing concern [13-15], which is why investigations of the antifungal potential of new molecules are highly relevant. Plants and their derivatives are an important source of bioactive molecules. Essential oils extracted from different parts of certain plants (leaves, flowers, seeds, bark, etc.) possess numerous therapeutic properties, including antimicrobial activities $[29,30]$. Moreover, proanthocyanidins, a family of polyphenols consisting of flavan-3-ol oligomers and polymers, have been proposed as promising molecules for treating oral infections given their anti-adherence and antiinflammatory properties [31]. The present study was designed to evaluate the effects of two cinnamon fractions, an essential oil and an aqueous extract enriched in proanthocyanidins, on both $C$. albicans (growth, biofilm formation, adherence properties) and oral epithelial cells (barrier integrity, inflammatory response). 

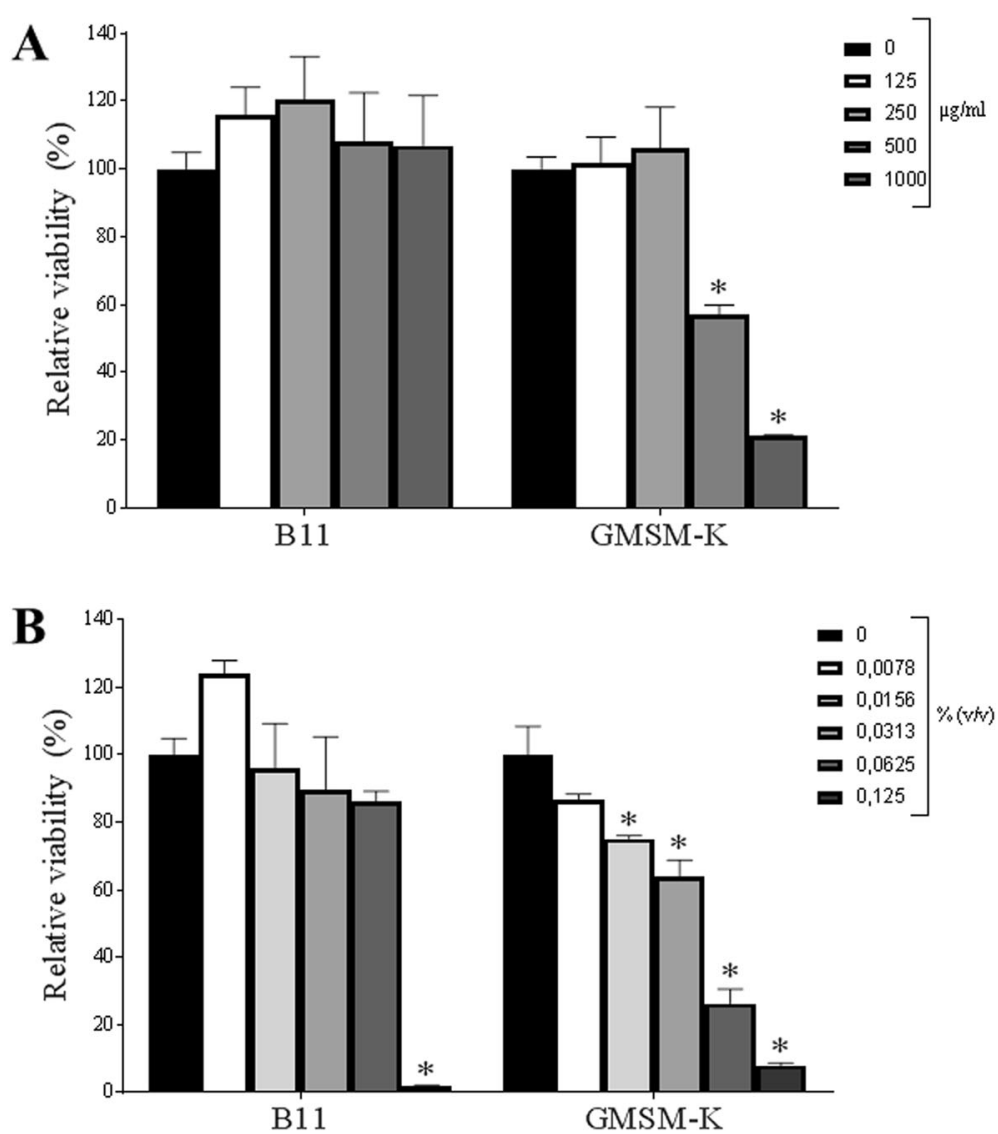

Fig. 6 Effect of Cinnulin PF (panel a) and cinnamon bark oil (panel b) on the viability of two oral epithelial cell lines (B11 and GMSM-K). The epithelial cells were treated for $16 \mathrm{~h}$ with the cinnamon fractions prior to determining cell viability using a colorimetric MTT assay. Results are expressed as the means \pm SD of triplicate assays in two independent experiments. ${ }^{*}$ : significantly different from the control $(p<0.01)$

We first showed that the growth of C. albicans was inhibited by cinnamon bark oil. Cinnulin $\mathrm{PF}^{\circ}$, had no effect on the growth of $C$. albicans, even at the highest concentration tested $(1000 \mu \mathrm{g} / \mathrm{mL})$. The ability of cinnamon oil to inhibit the growth of several oral microbial pathogens, including Porphyromonas gingivalis [32], Solobacterium moorei [20], Streptococcus mutans [33], and C. albicans [34] has been previously reported. Moreover, in a recent study, Essid et al. [34] showed that combining cinnamon oil with the antifungal drug fluconazole provided a synergistic effect against fluconazole-resistant Candida strains.

We then explored the mechanism by which the cinnamon bark oil exerts its antifungal effect against $C$. albicans. The ability of cinnamon oil to disrupt the cell membrane was assessed by SYTOX $^{\circ}$ Green staining, which showed that the antifungal activity of cinnamon oil may be due to its ability to damage the cell membrane. This is in agreement with Essid et al. [34], who reported that cinnamon essential oil inhibits ergosterol biosynthesis in Candida species, an effect that may have an impact on the integrity of the fungal membrane by permeabilizing the cell. However, despite the ability of cinnamon oil to cause damage to the cell membrane of C. albicans, additional mechanisms that may contribute to its fungicidal effect cannot be ruled out.

C. albicans forms biofilms on many oral surfaces, including tooth enamel, oral mucosa, implants, and dentures $[1,2]$. C. albicans cells embedded in a biofilm are more resistant to mechanical elimination by saliva and to antifungal agents compared with their planktonic counterparts [35-38]. Antimicrobial agents have difficulty penetrating a biofilm, which can reduce their effectiveness. Therapeutic strategies aimed at inhibiting biofilm formation are thus highly relevant. The present study showed that cinnamon bark oil at sub-inhibitory concentrations can inhibit C. albicans biofilm formation. Moreover, the treatment of a preformed $C$. albicans biofilm with cinnamon bark oil significantly reduced the viability of the biofilm. A very low concentration of Cinnulin $\mathrm{PF}^{\bullet}(\geq 31.25 \mu \mathrm{g} / \mathrm{mL})$ also significantly inhibited the formation of a biofilm by $C$. albicans. These results suggest that Cinnulin $\mathrm{PF}^{\bullet}$ may be a promising anti-C. albicans agent because it specifically acts on biofilm 

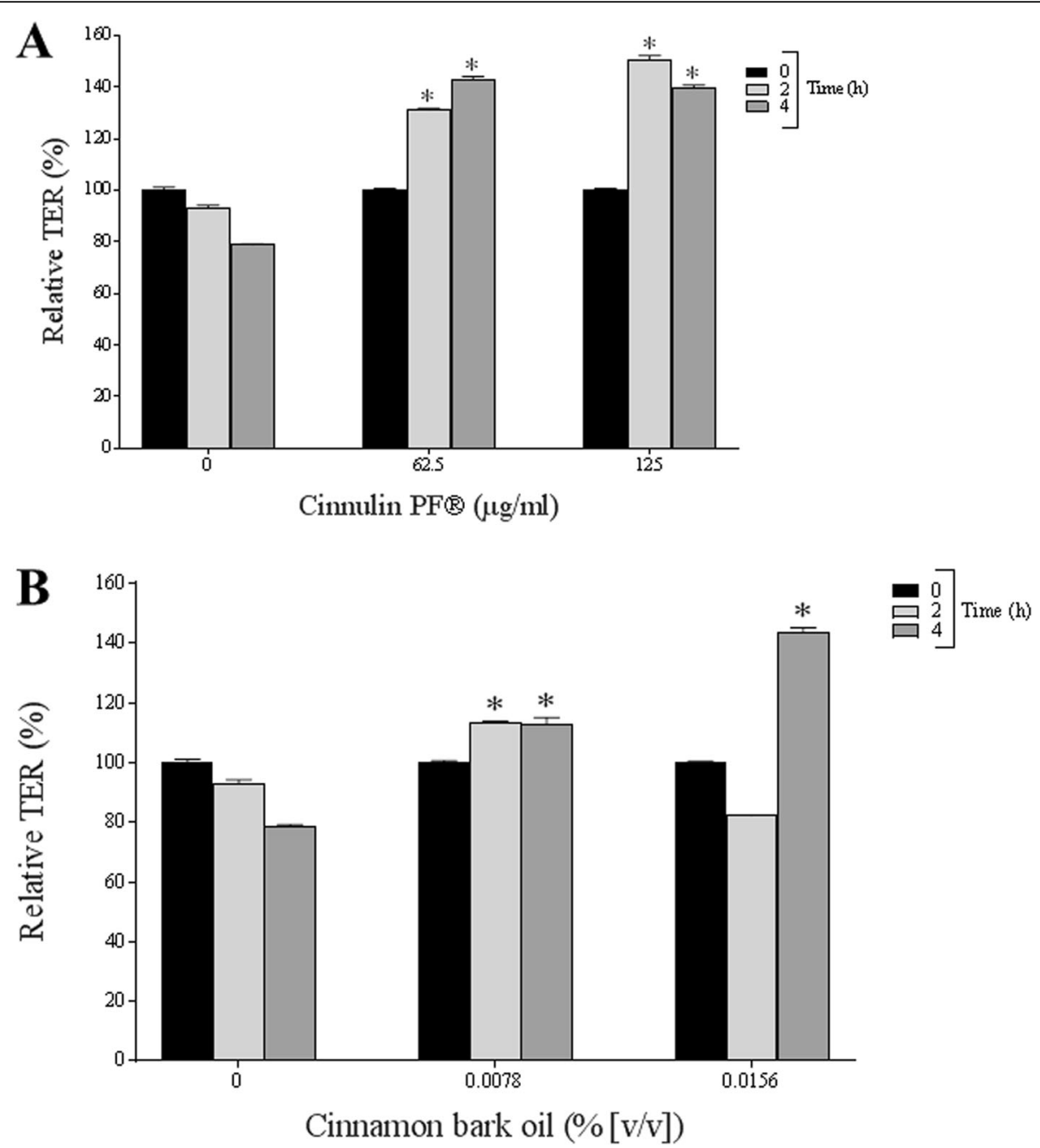

Fig. 7 Effect of Cinnulin PF (panel a) and cinnamon bark oil (panel b) on the integrity of the epithelial barrier (B11 cell line). The TER values were determined after a 6 -h incubation. A value of $100 \%$ was assigned to the TER values at time 0 . Results are expressed as the means \pm SD of triplicate assays. *: significantly different from the control $(p<0.01)$

formation, a critical step of the infectious process. Preliminary assays showed that Cinnulin $\mathrm{PF}^{\circ}$ had no effect on hyphae formation (data not shown). In vivo, biofilm formation by $C$. albicans requires initial adherence to the oral mucosa. Interestingly, Cinnulin $\mathrm{PF}^{\circ}$ significantly attenuated the adherence of $C$. albicans while no such effect was observed with cinnamon oil.

The oral epithelium protects the underlying tissues from microbial invasion and thus actively contributes to the maintenance of oral health [39]. This barrier effect is mediated by the tight junctions that seal the epithelial cells together. We thus investigated the ability of the cinnamon fractions to strengthen the epithelial barrier. Our results demonstrated that electrical resistance increased when the epithelial cells were cultivated in the presence of either cinnamon bark oil or Cinnulin PF. These results suggest that these cinnamon fractions, by reinforcing the epithelium, may potentially prevent the invasion of the oral mucosa by oral pathogens.

Although the host inflammatory response is key to maintaining oral health, an acute and exacerbated inflammatory reaction as observed in oral candidiasis and oral mucositis may be deleterious by causing tissue damage. More specifically, the development of oral mucositis in patients receiving chemotherapy and radiotherapy treatments involves the stimulation of infiltrating macrophages, resulting in the activation of $N F-k B[6,7]$. This process is associated with the secretion of inflammatory cytokines, including TNF- $\alpha$, that promote inflammation and tissue destruction. In the present study, when epithelial cells were challenged with TNF- $\alpha$, they secreted a large quantity of IL-6 and IL-8. These two pro-inflammatory cytokines are known to play a critical role for the recruitment 

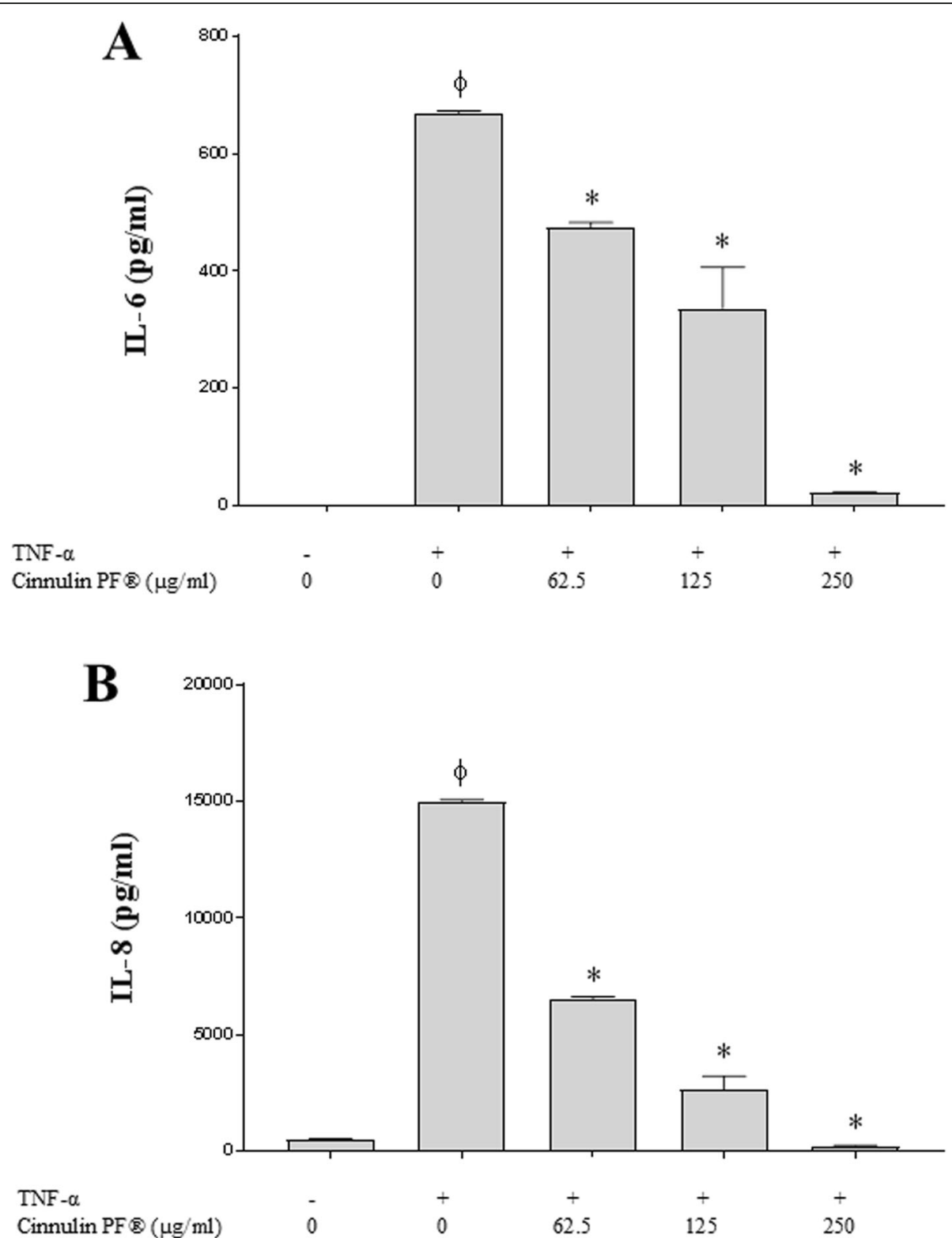

Fig. 8 Effect of Cinnulin PF on TNF-a-induced IL-6 (panel a) and IL-8 (panel b) secretion by oral epithelial cells (GMSM-K cell line). Results are expressed as the means \pm SD of triplicate assays in two independent experiments. ${ }^{*}$ : significantly different from the control $(p<0.01)$

and activation of neutrophils and macrophages at the site of infection [40, 41]. However, due to this protecting reaction of the host against fungal pathogens, an accumulation of inflammatory mediators occurs to induce a chronic and persistent inflammation, and ultimately tissue destruction. Therefore, preventing an excessive activation of innate immunoeffectors may be associated with resolution of the inflammatory process. In this study, we showed a dose-dependent inhibitory effect of Cinnulin $\mathrm{PF}^{\odot}$ on TNF- $\alpha$-induced secretion of IL- 6 and IL- 8 by oral epithelial cells.

In this study, we showed that the two cinnamon fractions under investigation share a number of common properties (anti-biofilm, tight junction promotion) but also exhibit some distinct features. More specifically, cinnamon essential oil inhibited C. albicans growth while Cinnulin $\mathrm{PF}^{\oplus}$ attenuated the epithelial cell inflammatory response. Therefore, combining the two cinnamon fractions may be a valuable therapeutic approach for the treatment of $C$. albicans infections through their effects on different targets.

\section{Conclusion}

By their ability to attenuate growth, biofilm formation and adherence property of $C$. albicans, to reinforce the epithelial barrier function, and to attenuate the 
inflammatory response of epithelial cells, the two cinnamon fractions (essential oil, Cinnulin $\mathrm{PF}^{\bullet}$ ) investigated in the present study may be promising agents for controlling C. albicans infections such as oral candidiasis, denture stomatitis, and Candida-infected oral mucositis lesions.

\section{Abbreviations}

DMEM: Dulbecco's Modified Eagle's Medium; ELISA: Enzyme-linked immunosorbent assay (ELISA); FBS: Fetal bovine serum; FITC: Fluorescein isothiocyanate; IL-6: Interleukin-6; IL-8: Interleukin-8; K-SFM: Keratinocyte serum-free medium; MFC: Minimum fungicidal concentration; MIC: Minimum inhibitory concentration; MTT: 3-[4,5-diethylthiazol-2-yl]2,5diphenyltetrazolium bromide; OD: Optical density; TER: Transepithelial electrical resistance; TNF-a: Tumor necrosis factor-alpha; XTT: 2,3-bis(2methoxy-4-nitro-sulfophenyl)-2H-tetrazolium-5-carboxanilide sodium salt

\section{Acknowledgements}

We are grateful to IN Ingredients Inc. (Spring Hill, TN, USA) for providing the Cinnulin PF⿻, S. Groeger (Department of Periodontology, Justus Liebig University Giessen, Germany) for providing the B11 cell line, and V. Murrah (University of North Carolina, Chapel Hill, NC, USA) for providing the GMSM-K cell line.

\section{Authors' contributions}

M-PV conducted the experiments, M-PV and DG analyzed the results. DG contributed reagents/materials. The manuscript was written by M-PV and DG. Both authors read and approved the final manuscript.

\section{Funding}

This work was supported by the Laboratoire de Contrôle Microbiologique de I'Université Laval (grant number 2019-03-21). This funding body had no role in the study design, data collection and analysis, or submission of the manuscript for publication.

\section{Availability of data and materials}

The datasets used and/or analysed during the current study are available from the corresponding author on reasonable request.

\section{Ethical approval and consent to participate}

No ethics approval was required because no experiments on humans or animals were carried out.

\section{Consent for publication}

Not applicable.

\section{Competing interests}

We wish to confirm that there are no known conflicts of interest associated with this publication and there has been no financial support for this work that could have influenced its outcome.

\section{Received: 7 June 2019 Accepted: 24 October 2019}

Published online: 08 November 2019

\section{References}

1. Rautemaa R, Ramage G. Oral candidosis - clinical challenges of a biofilm disease. Crit Rev Microbiol. 2011;37:328-36.

2. O'Donnell LE, Millhouse E, Sherry L, Kean R, Malcolm J, Nile CJ, Ramage G. Polymicrobial Candida biofilms: friends and foe in the oral cavity. FEMS Yeast Res. 2015:15-fov077.

3. Pappas PG. Invasive candidiasis. Infect Dis Clin N Am. 2006;20:485-506

4. Stringer AM, Logan RM. The role of oral flora in the development of chemotherapy-induced oral mucositis. J Oral Pathol Med. 2015;44:81-7.

5. Vanhoecke B, De Ryck T, Stringer A, Van de Wiele T, Keefe D. Microbiota and their role in the pathogenesis of oral mucositis. Oral Dis. 2015;21:17-30.

6. Al-Ansari S, Zecha JA, Barasch A, de Lange J, Rozema FR, Raber-Durlacher JE. Oral mucositis induced by anticancer therapies. Curr Oral Health Rep. 2015; 2:202-11.

7. Lalla RV, Saunders DP, Peterson DE. Chemotherapy or radiation-induced oral mucositis. Dent Clin N Am. 2014;58:341-9.
8. Höfs S, Mogavero S, Hube B. Interactions of Candida albicans with host cells: virulence factors, host defense, escape strategies, and the microbiota. J Microbiol. 2016;54:149-69.

9. Wachtler B, Wilson D, Haedicke K, Dalle F, Hube B. From attachment to damage: defined genes of Candida albicans mediate adhesion, invasion and damage during interaction with oral epithelial cells. PLoS One. 2011;6: e17046.

10. Williams DW, Jordan RP, Wei $X Q$, Alves $C T$, Wise MP, Wilson MJ, Lewis MA. Interactions of Candida albicans with host epithelial surfaces. J Oral Microbiol. 2013;5:22434.

11. Douglas LJ. Candida biofilms and their role in infection. Trends Microbiol. 2003;11:30-6.

12. Tsui C, Kong EF, Jabra-Rizk MA. Pathogenesis of Candida albicans biofilm. Pathog Dis. 2016;74:ftw018.

13. Cleveland AA, Harrison LH, Farley MM, Hollick R, Stein B, Chiller TM, Lockhart SR, Park BJ. Declining incidence of candidemia and the shifting epidemiology of Candida resistance in two US metropolitan areas, 20082013: results from population based surveillance. PLoS One. 2015;10: e0120452.

14. Ford CB, Funt JM, Abbey D, Issi L, Guiducci C, Martinez DA, Delorey T, Li BY, White TC, Cuomo C, Rao RP, Merman J, Thaompso DA, Regev A. The evolution of drug resistance in clinical isolates of Candida albicans. eLife. 2015:4:e00662.

15. Sanguinetti M, Posteraro B, Lass-Florl C. Antifungal drug resistance among Candida species: mechanisms and clinical impact. Mycoses. 2015;58:2-13.

16. Lu M, Li T, Wan J, Li X, Yuan L, Sun S. Antifungal effects of phytocompounds on Candida species alone and in combination with fluconazole. Int J Antimicrob Agents. 2017:4:125-36.

17. Ranasinghe P, Pigera S, Premakumara GAS, Galappaththy P, Constantine GR, Katulanda P. Medicinal properties of 'true' cinnamon (Cinnamomum zeylanicum): a systematic review. BMC Complement Altern Med. 2013;13:275.

18. Rao PV, Gan GH. Cinnamon: a multifaceted medicinal plant. Evid Based Complement Alternat Med. 2014;642942.

19. Mateos-Martín M, Fuguet E, Quero C, Pérez-Jiménez J, Torres J. New identification of proanthocyanidins in cinnamon (Cinnamomum zeylanicum L.) using MALDI-TOF/TOF mass spectrometry. Anal Bioanal Chem. 2012;402: 1327-36.

20. Pfaller MA, Sheehan DJ, Rex JH. Determination of fungicidal activities against yeasts and molds: lessons from bactericidal testing and the need for standardization. Clin Microbiol Rev. 2004;17:268-80.

21. LeBel G, Haas B, Adam AA, Veilleux MP, Lagha AB, Grenier D. Effect of cinnamon (Cinnamomum verum) bark essential oil on the halitosisassociated bacterium Solobacterium moorei and in vitro cytotoxicity. Arch Oral Biol. 2017:83:97-104.

22. Lagha AB, Dudonné S, Desjardins Y, Grenier D. Wild blueberry (Vaccinium angustifolium Ait.) polyphenols target Fusobacterium nucleatum and the host inflammatory response: Potential innovative molecules for treating periodontal diseases. J Agric Food Chem. 2015;63:6999-7008.

23. Morici P, Fais R, Rizzato C, Tavanti A, Lupetti A. Inhibition of Candida albicans biofilm formation by the synthetic lactoferricin derived peptide hLF1-11. PLoS One. 2016:11:e0167470.

24. Groeger S, Michel J, Meyle J. Establishment and characterization of immortalized human gingival keratinocyte cell lines. J Periodontal Res. 2008; 43:604-14.

25. Gilchrist EP, Moyer MP, Shillitoe EJ, Clare N, Murrah VA. Establishment of a human polyclonal oral epithelial cell line. Oral Surg Oral Med Oral Pathol Oral Radiol Endod. 2000;90:340-7.

26. Marquis A, Genovese S, Epifano F, Grenier D. The plant coumarins auraptene and lacinartin as potential multifunctional therapeutic agents for treating periodontal disease. BMC Complement Altern Med. 2012;12:80.

27. Ben Lagha A, Grenier D. Black tea theaflavins attenuate Porphyromonas gingivalis virulence properties, modulate gingival keratinocyte tight junction integrity and exert anti-inflammatory activity. J Periodontal Res. 2017;52: 458-70.

28. Belazi M, Velegraki A, Koussidou-Eremondi T, Andreadis D, Hini S, Arsenis G, Eliopoulou C, Destouni E, Antoniades D. Oral Candida isolates in patients undergoing radiotherapy for head and neck cancer: prevalence, azole susceptibility profiles and response to antifungal treatment. Oral Microbiol Immunol. 2004;19:347-51.

29. Bakkali F, Averbeck S, Averbeck D, Idaomar M. Biological effects of essential oils - a review. Food Chem Toxicol. 2008;46:446-75. 
30. Swamy MK, Akhtar MS, Sinniah UR. Antimicrobial properties of plant essential oils against human pathogens and their mode of action: an updated review. Evid Based Complement Alternat Med. 2016;3012462.

31. Feghali K, Feldman M, La VD, Santos J, Grenier D. Cranberry

proanthocyanidins: natural weapons against periodontal diseases. J Agric Food Chem. 2012;60:5728-35.

32. Wang Y, Zhang Y, Shi YQ, Pan XH, Lu YH, Cao P. Antibacterial effects of cinnamon (Cinnamomum zeylanicum) bark essential oil on Porphyromonas gingivalis. Microb Pathog. 2018;116:26-32.

33. Chaudhari LK, Jawale BA, Sharma S, Sharma H, Kumar CD, Kulkarni PA. Antimicrobial activity of commercially available essential oils against Streptococcus mutans. J Contemp Dent Pract. 2012;13:71-4.

34. Essid R, Hammami M, Gharbi D, Karkouch I, Ben Hamouda T, Elkahoui S, Limam F, Tabbene O. Antifungal mechanism of the combination of Cinnamomum verum and Pelargonium graveolens essential oils with fluconazole against Candida strains. Appl Microbiol Biotechnol. 2017;101: 6993-7006.

35. Chandra J, Mukherjee PK, Leidich SD, Faddoul FF, Hoyer LL, Douglas LJ, Ghannoum MA. Antifungal resistance of candidal biofilms formed on denture acrylic in vitro. J Dent Res. 2001;80:903-8.

36. Hawser SP, Douglas LJ. Resistance of Candida albicans biofilms to antifungal agents in vitro. Antimicrob Agents Chemother. 1995;39:2128-31.

37. Ramage G, Wickes BL, Lopez-Ribot JL. Biofilms of Candida albicans and their associated resistance to antifungal agents. Am Clin Lab. 2001;20:42-4.

38. Ramage G, VandeWalle K, Bachmann SP, Wickes BL, Lopez-Ribot JL. In vitro pharmacodynamic properties of three antifungal agents against preformed Candida albicans biofilms determined by time-kill studies. Antimicrob Agents Chemother. 2002;46:3634-6.

39. Groeger SE, Meyle J. Epithelial barrier and oral bacterial infection. Periodontol 2000. 2015;69:46-67.

40. Jones SA. Directing transition from innate to acquired immunity: defining a role for IL-6. J Immunol. 2005;175:3463-8.

41. Rossi D, Zlotnik A. The biology of chemokines and their receptors. Annu Rev Immunol. 2000;18:217-42.

\section{Publisher's Note}

Springer Nature remains neutral with regard to jurisdictional claims in published maps and institutional affiliations.

Ready to submit your research? Choose BMC and benefit from:

- fast, convenient online submission

- thorough peer review by experienced researchers in your field

- rapid publication on acceptance

- support for research data, including large and complex data types

- gold Open Access which fosters wider collaboration and increased citations

- maximum visibility for your research: over $100 \mathrm{M}$ website views per year

At $\mathrm{BMC}$, research is always in progress.

Learn more biomedcentral.com/submissions 